\title{
PADRÃO LESIONAL DA MEDULA ÓSSEA NA IMUNODEFICIÊNCIA ADQUIRIDA (AIDS)
}

\author{
M. BARRETTO NeTTo (1), Enoi Aparecida Guedes VILAR (2), Letícia Maria Boechat ANDRADE (3),
} Rita de Cássia Lauria G. da SILVA (4) \& Maria Inês K. Praxedes Baeta NEVES (5).

\begin{abstract}
RESUMO
O estudo da medula óssea em 20 casos de necrópsia de pacientes portadores da Sindrome da Imunodeficiência Adquirida sugere que as alteraçōes medulares são freqüentes e de valor diagnóstico no reconhecimento da Síndrome. É admitida a existência de um padrāo lesional diagnóstico onde predominam os seguintes elementos: hipercelularidade, ausência ou redução da granulopoiese, plasmocitose, his tiocitose e displasia megacariocítica.
\end{abstract}

UNITERMOS: Histopatologia da medula óssea na AIDS; Mielodisplasia na AIDS.

A incidência de alteraçōes hematológicas em pacientes acometidos pela Síndrome da Imu nodeficiência Adquirida é relativamente elevada SPIVAK e col. ${ }^{10}$ observaram anemia em $78 \%$, leucopenia em $34 \%$ e linfopenia em $84 \%$ dos pacientes com AIDS.

Todavia, são raros os estudos relacionados com a histopatologia da medula óssea, particularmente em material de necrópsia, de pacientes com AIDS. Desta forma, julgamos de interesse relatar os nossos achados no estudo de 20 casos de AIDS necropsiados no Departamento de $\mathrm{Pa}$ tologia e Apoio Clínico do Hospital Universitário Antonio Pedro, da UFF.

\section{MATERIAL E MÉTODOS}

O material de estudo correspondeu a fragmentos ósseos de corpos vertebrais de 20 necróp sias de pacientes portadores de Sindrome de Imunodeficiência Adquirida, diagnosticados de acordo com a sintomatologia dominante (febre, diarréia, astenia, prostração, emagrecimento acentuado e comprometimento neurológico), quadro hematológico (leucopenia, linfopenia e plaquetopenia, em número variável de casos) e HIV positivo em quase todos os casos, ao lado de afecçōes oportunisticas freqüentemente associadas à AIDS (Quadro 1).

Trabalho do Departamento de Patologia e Apoio Clínico da Universidade Federal Fluminense (UFF) - Hospital Universitário Antonio Pedro, Niterói, Rio de Janeiro, Brasil.

(1) Professor Titular de Anatomia Patológica do Departamento de Patologia da UFF.

(2) Professor Assistente de Anatomia Patológica do Departamento de Patologia da UFF

(3) Professor Assistente de Imunopatologia do Departamento de Patologia da UFF

(4) Médico Residente do Serviço de Anatomia Patológica do Departamento de Patologia da UFF.

(5) Médico Residente do Serviço de Anatomia Patológica do Departamento de Patología da UFF.

Endereço para correspondência: Prof. Manoel Barretto Netto. Hospital Universitário Antonio Pedro. Rua Marquês do Paraná, 303. CEP 24030 Niterói, RJ, Brasil. 
BARRETO NETTO. M.; VILAR, E. A. G.: ANDRADE. L M. B.: SILVA. R. de C. L. G. \& NEVES. M. I. K. P. B. - Padráo lesional da medula óssea na imunodeficiència adquirida (AIDS). Rev. Inst. Med. trop. Sáo Paulo, 30 (4): 253258,1988

QUADRO

Representaça dos principais aspectos dos 20 casos estudados

\begin{tabular}{|c|c|c|c|c|c|c|c|c|c|c|}
\hline $\operatorname{caso}$ & Registro & Sexo & Idade & Principais Sintomas & Alt Hematol & Afecçoes oportunisticas & Grupo de riseo & Anti Hix & Celul & Granulup. \\
\hline 1 & $\sqrt{84312}$ & $\mathrm{~F}$ & 23 & $\begin{array}{l}\text { Diareia febre astenta adenomegalia. } \\
\text { Irritacao meningea convulsao }\end{array}$ & $\begin{array}{l}\text { Anemia, leucope } \\
\text { nia, linfopenia }\end{array}$ & $\begin{array}{l}\text { Toxoplasmose cerebral e } \\
\text { miocardica, moniliase. }\end{array}$ & Transfusional & Nan real & ++ & 0 \\
\hline 2 & N85 137 & M & 22 & Emagrecimento. prostraça o, coma & $\begin{array}{l}\text { Leucopenia. } \\
\text { Linfopensa }\end{array}$ & $\begin{array}{l}\text { Toxoplasmose cerebral e } \\
\text { miocárdica. candidiase } \\
\text { pulmonar tuberculose } \\
\text { pulmonar }\end{array}$ & Homossexual & Positivo & ++ & 0 \\
\hline 3 & N85 170 & $\mathrm{M}$ & 20 & $\begin{array}{l}\text { Febre obscura. septicemia, hemiplegia } \\
\text { coma }\end{array}$ & $\begin{array}{l}\text { Leucopenia. } \\
\text { Linfopena }\end{array}$ & Toxoplasmose cerebral & $? ? ?$ & Positivo & $++t$ & - \\
\hline 4 & N85 17i & $\mathrm{M}$ & 25 & Diarréia, adenomegalia, convulsảo & $\begin{array}{l}\text { Anemia, leucope } \\
\text { nia. linfopenia }\end{array}$ & $\begin{array}{l}\text { Toxoplasmose cerebral. } \\
\text { Esofagite herpetica }\end{array}$ & $? ?$ & Positivo & ++ & 0 \\
\hline 5 & N85 229 & $\mathrm{M}$ & 42 & $\begin{array}{l}\text { Febre, astenia, caquexia, processo } \\
\text { expansivo cerebral. hemiplegja }\end{array}$ & $\begin{array}{l}\text { Anemia, leurope } \\
\text { nia. Iinfopenia }\end{array}$ & $\begin{array}{l}\text { Tuxophasmost terbet } \\
\text { criptococose pulmonar }\end{array}$ & Homossexual & Positivo & $\cdots+$ & 0 \\
\hline 6 & N85 242 & $\mathrm{M}$ & 22 & $\begin{array}{l}\text { Diarréia, febre, ictericia, insuficiencia } \\
\text { respiratoria }\end{array}$ & $\begin{array}{l}\text { Leucocitose } \\
\text { linfopenia }\end{array}$ & $\begin{array}{l}\text { Candidaste metes!mat. } \\
\text { esofagite }\end{array}$ & $\begin{array}{l}\text { Homossexual, } \\
\text { toxicomania }\end{array}$ & Posituvo & ++ & 0 \\
\hline 7 & N85.209 & $\mathrm{M}$ & 40 & $\begin{array}{l}\text { Septicemia, peric ardite } \\
\text { hepatomegalla, ictericia }\end{array}$ & & $\begin{array}{l}\text { Tuberculose pulmonar. } \\
\text { ht:patle grantiomatosa. } \\
\text { perieardite purulenta. } \\
\text { mincardite }\end{array}$ & Homossexual & Positivo & +++ & - \\
\hline 8 & N86 12 & $\mathrm{M}$ & 31 & $\begin{array}{l}\text { Diarreia, febre moniliase oral. } \\
\text { adenomegalia, tosse. dispneiia. } \\
\text { hepatoesplenomegalia, ictericia. }\end{array}$ & $\begin{array}{l}\text { Anemia. Jeueope } \\
\text { nia. linfopenta }\end{array}$ & 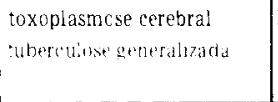 & Homossexual & Positivo & +++ & 0 \\
\hline 9 & N86 77 & M & 28 & $\begin{array}{l}\text { Febre emagrecimento, candidiase oral, } \\
\text { hemorragia digestiva. insuficiencia } \\
\text { hepatica. renal e respiratoria }\end{array}$ & $\begin{array}{l}\text { Leucopenia, } \\
\text { linfopenia }\end{array}$ & Histoplasmose generalizada & Bissexual & Positivo & $+t+$ & 0 \\
\hline 10 & N86 178 & $F$ & 54 & $\begin{array}{l}\text { Febre anorexia. adenomegahia. } \\
\text { insuficiencia renal cronica. } \\
\text { hepatoesplenomegalia }\end{array}$ & $\begin{array}{l}\text { Anemia. letucoci } \\
\text { tose. Jinfocitose }\end{array}$ & Colite ulcerada & $\begin{array}{l}\text { Transfusional } \\
\text { I. renal cron. }\end{array}$ & Positivo & ++ & - - \\
\hline 11 & N86 192 & M & 42 & $\begin{array}{l}\text { Nodulos de regiao plantar e cervical. } \\
\text { infil traçán nodular bilateral de } \\
\text { pulmào. abscessos peri anais. } \\
\text { insuficiéneia respiratória }\end{array}$ & & $\begin{array}{l}\text { Sarcoma de Kaposi pele. } \\
\text { esofago. pulmāol toxoplasmose } \\
\text { corebral, citomegalovirus } \\
\text { pulmào e cerebrol }\end{array}$ & ??? & Positivo & +++ & - \\
\hline 12 & N86 200 & M & 53 & $\begin{array}{l}\text { Diarreia, febre, emagrecimento. } \\
\text { astenia. ictericia }\end{array}$ & $\begin{array}{l}\text { Aremia leucoei } \\
\text { tose. linfopenia }\end{array}$ & $\begin{array}{l}\text { Toxoplasmose cerebral e } \\
\text { miocardica }\end{array}$ & Homossexual & Positivo & ++ & - \\
\hline 13 & N86 209 & $\mathrm{M}$ & 32 & $\begin{array}{l}\text { Diarréia, febre, emagrecimento, } \\
\text { vómitos, cefalélá }\end{array}$ & Linfopenia & $\begin{array}{l}\text { Toxoplasmose cerebral. } \\
\text { citomegaluviruse pulmonar }\end{array}$ & $\begin{array}{l}\text { Homossexual. } \\
\text { toxicomania }\end{array}$ & Positjvo & +++ & - \\
\hline 14 & N86 272 & $\mathrm{M}$ & 43 & Diarréia, fébre. emagrecimento & & $\begin{array}{l}\text { Citomegalovirose (pulmào, } \\
\text { figado, intestino, coração. } \\
\text { adrenalı }\end{array}$ & Transfusional & Positivo & ++ & - \\
\hline 15 & N87 02 & $\mathrm{~F}$ & 38 & Sepsis, pneumopatia, crise convulsiva & & $\begin{array}{l}\text { Toxoplasmose cerebral. } \\
\text { tuberculose generalizada }\end{array}$ & $? ? ?$ & Nào real & $+t$ & 0 \\
\hline 16 & N87 20 & $\mathrm{M}$ & 40 & $\begin{array}{l}\text { Diarréia, febre, astenia, } \\
\text { emagrecimento, descerebraçào }\end{array}$ & $\begin{array}{l}\text { Anemia. leucope } \\
\text { nia. linfopenia }\end{array}$ & $\begin{array}{l}\text { Toxoplasmose cerebral. } \\
\text { mocardite. hepatite. } \\
\text { tuberculose pulmonar }\end{array}$ & $? ? ?$ & Nào real & +++ & - \\
\hline 17 & N87 41 & $F$ & 22 & $\begin{array}{l}\text { Sind. Von Willebrand. febre, rigidez de } \\
\text { puca. cefaleia, paresia facial }\end{array}$ & Linfopenta & Toxoplasmose cerebral & Transfusional & Negativo & ++ & - \\
\hline 18 & (N87-58) & $\mathrm{M}$ & 25 & $\begin{array}{l}\text { Diarréia, tosse, dispneia, cianose. } \\
\text { mancha perna esquerda, febre }\end{array}$ & $\begin{array}{l}\text { Anemia, linfope. } \\
\text { nia }\end{array}$ & $\begin{array}{l}\text { Sarcoma de Kaposi } \\
\text { pulmao, tracueia, lingua, } \\
\text { ganglios! }\end{array}$ & $\begin{array}{l}\text { Homossexual } \\
\text { transfusional }\end{array}$ & Positivo & $+t$ & - \\
\hline 19 & N87 267 & $\mathrm{M}$ & 39 & $\begin{array}{l}\text { Febre, tosse, insufieiència respiratória } \\
\text { aguda }\end{array}$ & $\begin{array}{l}\text { Leucocitosé. } \\
\text { linfopenia }\end{array}$ & $\begin{array}{l}\text { Pneumocistis carini, } \\
\text { citonegalovirose }\end{array}$ & Homossexual & Positivo & +++ & - \\
\hline 20 & N87 134 & M & 40 & $\begin{array}{l}\text { Sepsis, pericardite. ictericia. } \\
\text { insuficiencia respiratoria }\end{array}$ & & Tuberculose & Homossexual & Positivo & +++ & - \\
\hline
\end{tabular}


BARRETO NETTO, M.; VILAR, E. A. G.: ANDRADE, L. M. B.: SILVA, R. de C. L. G. \& NEVES, M. I. K. P. B - Padrào lesional da medula óssea na imunodeficiência adquirida (AIDS). Rev. Inst. Med. trop. Sảo Paulo, 30 (4): $253-258,1988$.

Os fragmentos foram fixados em formol a $10 \%$, incluídos em parafina, após descalcificaçāo, e corados pela Hematoxilina-Eosina, Tricrô mico e Reticulina de Gomori e PAS.

Como controle foi estudada a medula óssea de 20 casos de necrópsias, de várias condiçōes patológicas, em que predominavam os casos de septicemia.

\section{RESULTADOS}

A celularidade, avaliada pela proporção en tre células e vesículas de gordura em 5 campos microscópicos foi considerada aumentada em todos os casos, (Quadro 2). O aumento acentuado da celularidade em casos de AIDS foi significativo, quando comparado com o grupo controle (50\% e $5 \%$ ) (Quadro 2). A granulopoiese era au sente em 9 casos e reduzida em 1. A ausência de granulopoiese foi significativa quando com-

QUADRO 2

Principais alteraçôes da medula óssea

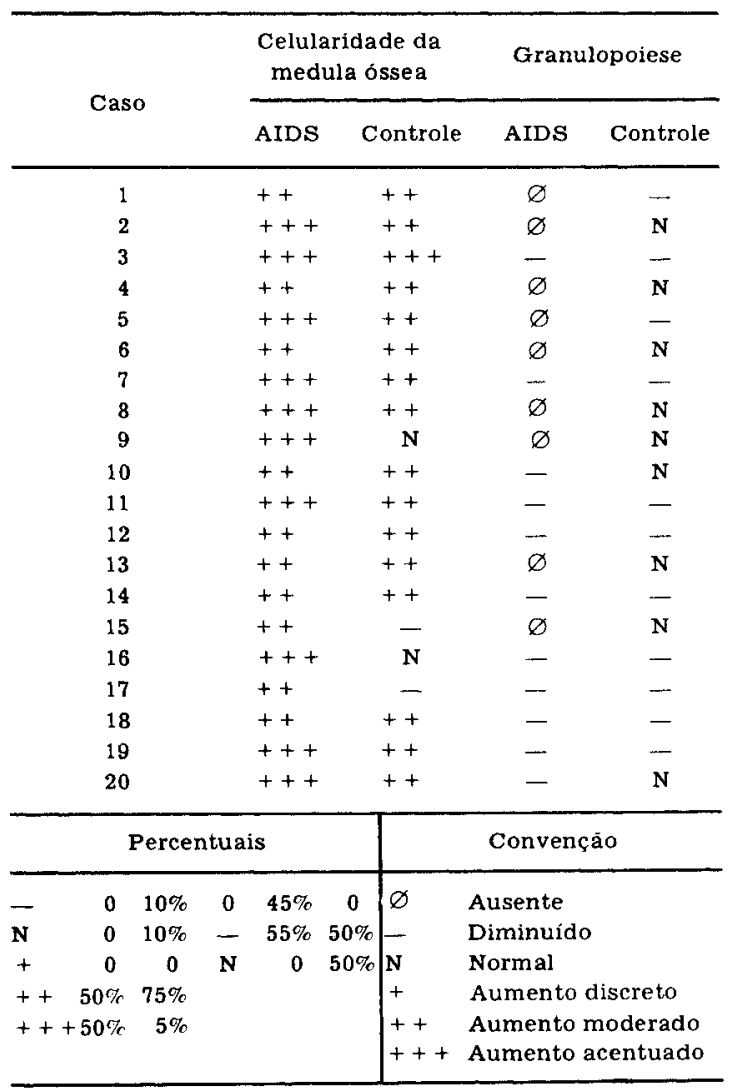

parada com o grupo controle (Quadro 2). A eritropoiese era diminuida em 9 casos e normal ou aumentada nos restantes, apresentando-se ge ralmente sob a forma de pequenos aglomerados irregularmente distribuídos. Histiócitos foram identificados em 17 dos 20 casos, sendo observada atividade macrofágica em 5 . Em todos os casos observou-se plasmocitose, mais intensa em 6 casos, com presença coincidente de corpúsculos de Russel em 16 casos. Em 11 casos foi verificada infiltração linfocitária e em 14 presença de eosinófilos.

O aumento de fibras reticulínicas foi constatado em 8 casos.

Os megacariócitos eram em número aumentado em 10 casos com modificaçōes estruturais significativas na totalidade dos casos.

\section{DISCUSSÃo}

Analisando um aspirado de medula óssea em um caso de AIDS com pancitopenia, SPIVAK e col. ${ }^{9}$, salientaram a existência de uma hemofagocitofagia histiocitica, enquanto a biópsia de medula óssea mostrava-se hipocelular, com linfócitos atípicos e aumento da reticulina. Esses autores admitiram que as alteraçóes da medula óssea encontradas em seu paciente com AIDS reproduziam de perto a "Síndrome hemofagocítica associada a virus" descrita por RISDALL e col. ${ }^{7}$, em 1979, em pacientes imunodeprimidos. As alteraçōes hematológicas seriam muito provavelmente a conseqüencia de uma infecçāo viral persistente em hospedeiro imunocomprometido.

Em trabalho posterior, SPIVAK e col. ${ }^{10}$ estu daram biópsias de medula óssea de 12 pacientes com Sindrome de Imunodeficiência Adquirida, dos quais 10 eram anêmicos, 8 leucopênicos e 3 trombocitopênicos. A celularidade era aumentada em cinco pacientes e reduzida em três. Os achados mais significativos foram a infiltração por plasmócitos, linfócitos e histiócitos, muitos destes fagocitando hemácias, leucócitos e plaquetas. Na grande maioria dos casos foi observado um aumento da reticulina da medula óssea.

FRANCO e cols. ${ }^{4}$ após mencionarem o fato de que a medula óssea tenha sido estudada ape- 
BARRETO NetTo, M.; VILAR, E. A. G.: ANDRADE. L. M. B.: SILVA. R. de C. L. G. \& NEVES. M. I. K. P. B - Padrão lesional da medula óssea na imunodeficiencia adquirida (AIDS). Kev. Inst. Med. trop. Sáo Paulo, 30 (4): 253258,1988 .

nas em casos esporadicos de AIDS, geralmente visando a avaliação de infecçōes oportunisticas, analisaram aspirados e biópsias de crista ilíaca de 12 pacientes portadores da Sindrome de Imu nodeficiencia Adquirida. As alteraçōes encon tradas corresponderam à plasmocitose, histio citose atípica, agregados linfóides atípicos e dila taçāo dos canais vasculares da medula.

HROMAS e col. ${ }^{6}$ fizeram o estudo compa rativo da biópsia de medula de 8 pacientes porta dores de AIDS e de 11 casos controle, portadores de tumores sólidos localizados, sem evidéncias histológicas de invasāo medular. Eles confirma ram o achado de uma plasmocitose e de uma eosinofilia relativas, comparadas com o contro le.

A importância diagnóstica da biópsia de medula óssea em pacientes portadores de Síndrome de Imunodeficiència Adquirida foi admitida por GELLER e cols. ${ }^{5}$, os quais sugeriram um "pacirào de AIDS" caracterizado por: 1) medula óssea hi percelular; 2 ) aumento difuso do número de célu las granulocíticas imaturas e diminuição das for mas segmentadas; 3 ) diminuiçāo relativa do nù mero de precursores eritróides; 4) aumento do número de megacariócitos; 5 ) aumento do núme ro de eosinófilos; 6) aglomerados esparsos de grandes linfócitos; 7) aumento da reticulina. A hiperplasia megacariocitica estava presente em $58 \%$ dos espécimens. CASTELLA e col. ${ }^{1}$ admi tiram que certos achados histológicos da medula óssea podem sugerir fortemente o diagnóstico da AIDS.

SCHNEIDER \& PICKER ${ }^{8}$ descreveram uma mielodisplasia no esfregaço de medula ós. sea de pacientes com infeç̧āo pelo HIV, a qual consideram um forte indicador da ação daquele virus sobre a medula óssea. Anomalias da granu lopoiese foram também destacadas. A mielodis plasia foi também observada por DELACRETAZ e col. ${ }^{2}$ em espécimens de medula óssea embebidas em plástico. Estes autores descreveram também uma dismegacariocitopoiese e uma diseritropoiese como o mais freqüente achado em seus 18 pacientes com infecçâo pelo HIV ( $88 \%$ e $83 \%$, respectivamente).

O distúrbio da granulopoiese na AIDS foi confirmado e destacado por D'ONOFRIO e col. ${ }^{3}$, que observaram uma disgranulopoiese em 9 pa cientes com AIDS, em cujos neutrofilos circu lantes foi constatado um aumento consistente da peroxidase. Os autores observaram ainda a presença de neutrófilos gigantes, atípicos, com núcleos irregulares e citoplasma abundante car regado de granulaçóes peroxidase positivas Tais células foram consideradas por esses auto res como a expressão mais comum da disgranu lopoiese na AIDS.

A avaliaçāo conjunta dos nossos casos corro boram a opiniāo de GELLER e cols. que suge rem a existência de um padrāo morfológico da medula óssea diagnóstico da AIDS

Dos vários elementos que contribuem para a constituiçāo desse padrào, destacamos como mais significativos os seguintes:

1. Aumento da celularidade da medula óssea, com conseqüente reduçảo do número de vesí culas de gordura. (Fig. 1).

2. Ausência ou redução acentuada da granulo poiese. (Fig. 2).

3. Plasmocitose, presente em todos os casos, por vezes muito acentuada, acompanhada da pre sença de corpúsculos de Russel. Figs. 3 e 4.

4. Histiocitose, de grau variável, as vezes com atividade macrofágica. (Fig. 5 ).

5. Hiperplasia dos megacariócitos, com presença de formas imaturas e en maturação, ao lado de células necrosadas ou degeneradas. (Fig. 6).

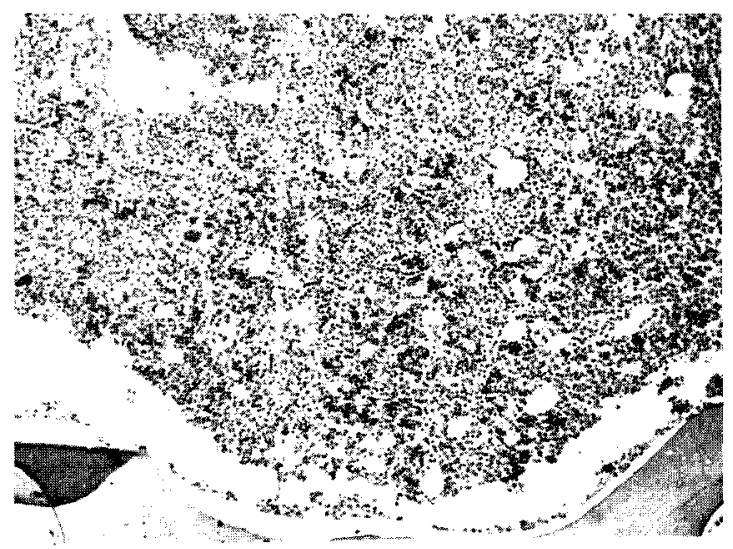

Fig. 1 - N.84.312- HE - Oc. 12x. obj. 10x. Aspecto compacto da medula óssea com acentuada reduçào do numero de vesicu las de gordura. 
BARRETO NETTO, M.: VILAR, E. A. G.: ANDRADF, L. M. B : SILVA, R. de C. L. G. \& NEVES, M. I. K. P. B. - Padrão lesional da medula ússea na imunodeficiencia adquirida tAIDSi. Rev. Inst. Med. trop. Sáo Paulo, 30 (4): 253258.1988

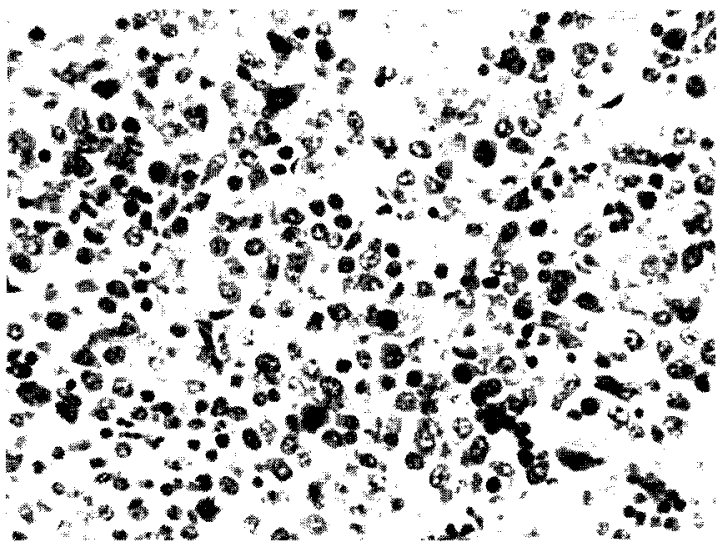

Fig. 2 - N.85.171 - HE -- Oc. $12 \mathrm{x}$, obj. $40 \mathrm{x}$. Hipercelularidade da medula óssea: ausência de granulopoiese; pequenos aglome rados de eritroblastos; plasmocitose.

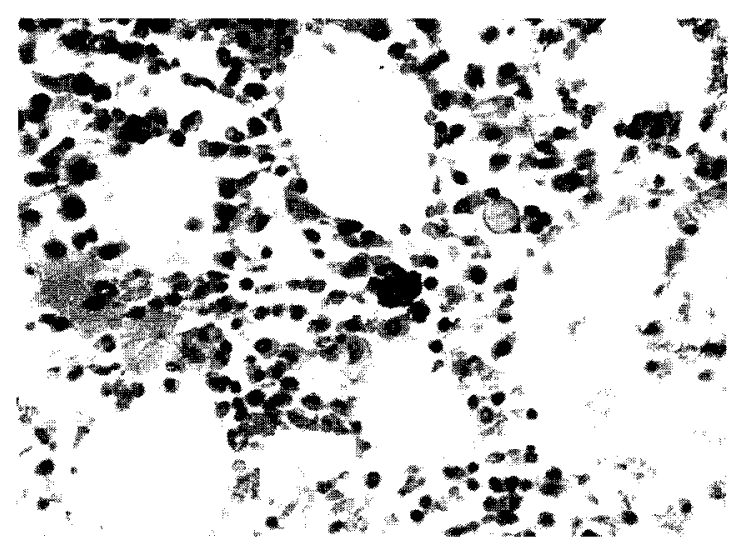

Fig. 3 - N.87.67 - HE - Oc. 12x, obj. 40x. Hipercelularidade: plasmocitose e histiocitose. Ausencia de elementos da série granulocitica: presença de pequenos focos de eritroblastos

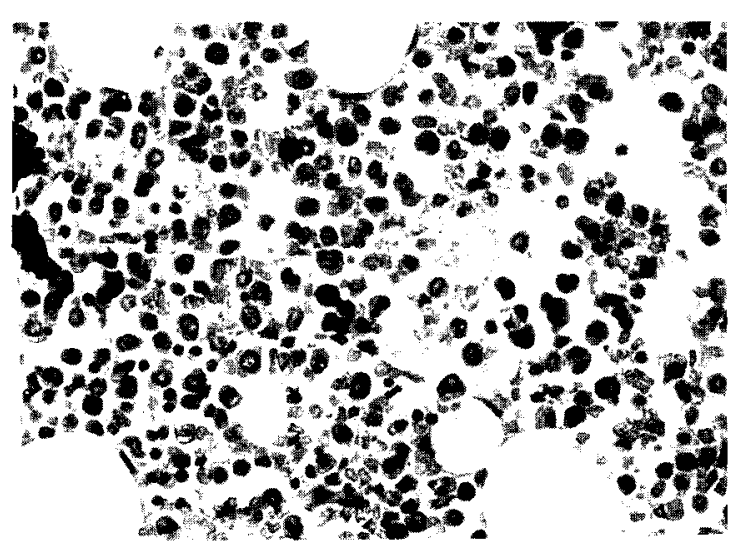

Fig. 4-N.87.67 - HE - Oc. $12 x$ obj. 40x. Detalhe da infil traçäo plasmocitária. Presenca de alguns histiócitos.

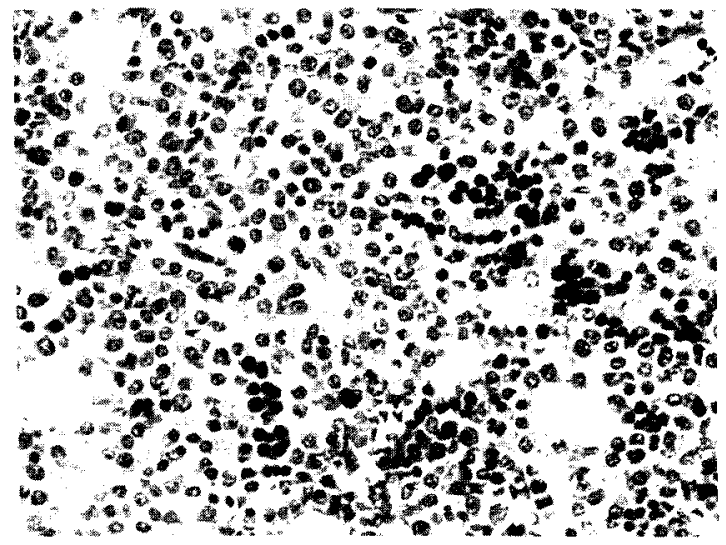

Fig. 5 -- Tricrómico de Gomori. Oc. $12 \mathrm{x}$, obj. $40 \mathrm{x}$. Histiocitose.

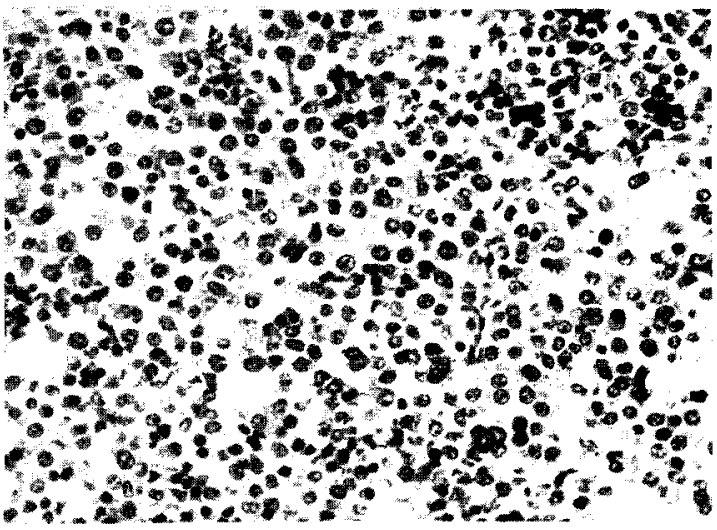

Fig. 6 - A 85.19 - HE - Oc. 12x, obj. 4UX. Megacarlocitos necrosados ou degenerados. Ao centro, um megacariócito imaturo e um corpúsculo de Russel.

Do estudo comparativo da medula óssea de pacientes com AIDS com a de um grupo con trole de autópsia de pacientes com outraś afecçóes, em que a septicemia predominava como causa de morte, o aumento da celularidade e a ausência ou diminuição da granulopoiese foram os achados mais significativos. (Quadro 2).

\section{SUMMARY}

$$
\text { “AIDS - pattern" of Bone Marrow }
$$

The bone marrow of 20 autopsy cases of pa tients with Acquired Immune Deficiency Syndrome was examined. The study suggests that the bone marrow changes are frequent and of diagnostic value to recognize the syndrome. It 
BARRETO NetTo, M.: VILAR, E. A. G; ANDRADE, L. M. B.: SILVA. R. de C. L. G. \& NEVES, M. I. K. P. B - Padrào lesional da medula ossea na imunodeficiencia adquirida (AIDS). Rev. Inst. Med. trop. Sáo Paulo, 30 (4): $253,258,1988$.

is assumed that there is a diagnostic lesional pattern in which the following elements are pre. dominant: hypercellularity, absent or reduced granulopoiesis, plasmocy tosis, histiocytosis and megakariocytic dysplasia.

\section{REFERENCIAS BIBLIOGRÁFICAS}

1. CASTElla A.: CROXSON, T. S : MILDVAN. D : WITT. D. H. \& ZALUSKY, R. - The bone marrow in AIDS. A histologic, hematologic and microbiologic study. Amer. J. clin. Path., 84: 425-432, 1985.

2. DELACRETAZ, F.: PEREY, L.: SCHMIDT, P, M.: CHA RE, J.P.; \& COSTA. J. - Histopathology of bone marrow in human immunodeficiency virus infection. Virchows Areh. A., 411: 543-551, 1987.

3. D'ONOFRIO, G.; MANCINI, S : TAMBURRINI, E.; MAN GO, G. \& ORTONA, L. - Giant neutrophils with increa sed peroxidase activity. Another evidence of dysgranulo poiesis in AIDS. Amer. J. clin. Path., 87: 584-591, 1987.
4. FRANCO, C. M : HENDRIX, L. E \& LOKEY, J. E Bone marrow abnormalities in the acquired imunodef ciency syndrome. Ann. intern. Med., 101: 275-276. 1984.

5. GELLER, S. A.: MULLER, R: GREENBERG. M. L. \& SIEGAL, F. P. - Acquired immunodeficiency.syndrome Distinctive feature of bone marrow biopsies. Arch. Path. Lab. Med., 109: 138-141, 1985

6. HROMAS, R. A.; MURRAY, J. L - Bone marrow in the acquired immunodeficiency syndrome. Ann. intern. Med., 101: 877,1984

7. RISDALL, R J ; MCKENNA, R. W. NESBIT, M E.; KRIVIT, W.; BALFOUR, H. H.: SIMMONDS, R. I. \& BRUNNING, R. D. - Virus associated hemophagocytic syndrome. Cancer, 44: 993.1002, 1979.

8. SCHNEIDER, D. R. \& PICKER, L. J. - Myelodysplasia in the AIDS. Amer. J. clin. Path., 84: 144-152, 1985.

9. SPIVAK, J.L.; SELONICK, S.E. \& QUINN, T.C. - Acquired immunodeficiency syndrome and Pancytopenia. J. Amer. med. Ass., 250: 3084-3087, 1983

10 SPIVAK J L BENDER B. S. \& QUINN, T. C. - Hemato logic abnormalities in the acquired immunodeficiency syndrome. Amer. J. Med., 77: 224-228, 1984

Recebido para publicaçāo em 8/9/1987. 